\title{
P-0962 FINDRISK score in assessment of 10 years risk of type 2 diabetes among people of Uzbek nationality
}

Ismailov S.I., Alieva A.V., Rakhimova G.N.

Tashkent Pediatric Medical Institute

Republican Specialized Scientific-and-Practical Medical Centre of Endocrinology named after academician Ya.Kh.Turakulov under the Ministry of Health of the Republic of

Uzbekistan

Tashkent Institute of Postgraduate Medical Education

Objective: to assess 10 years risk of type 2 DM among people of Uzbek nationality using FINDRISK questionnaire.

Materials and methods: we performed screening for DM and prediabetes among 2159 Uzbek people living in urban and rural settings aged 35 and older. Screening consisted of two stages:

1) filling in the questionnaire of DM based on the FINDRISK;

2) oral glucose tolerance test (OGTT) with $75 \mathrm{~g}$ of glucose to all individuals regardless of the assessed risk.

DM and prediabetes were diagnosed according to IDF recommendations.

Results: among people without carbohydrate metabolism disorders, 95\% had increased and moderate risk (FINDRISK score $\leq 14$ points).

Among people with IGT, only $25 \%$ had high DM risk, $26 \%$ had moderate risk, $28 \%$ had increased risk, and $17 \%$ had low risk.

Among people with DM diagnosed during the screening, only $30 \%$ had high and $4 \%$ had very high DM risk, whereas $28 \%$ had moderate risk, $30 \%$ had increased risk, and $9 \%$ had low risk of type 2 DM.
Table 1. Mean FINDRISK Score among people with revealed carbohydrates metabolism disorders comparing to the subjects carbohydrates metabolism disorders

\begin{tabular}{|l|c|}
\hline \multicolumn{1}{|c|}{ Group (n) } & Mean FINDRISK Score \\
\hline $\begin{array}{l}\text { No carbohydrates } \\
\text { metabolism disorders } \\
\text { during screening (1929) }\end{array}$ & $8.0 \pm 0.09$ \\
\hline $\begin{array}{l}\text { Newly diagnosed diabetes } \\
\text { mellitus (114) }\end{array}$ & $12.8 \pm 0.4^{*}$ \\
\hline $\begin{array}{l}\text { Impaired glucose } \\
\text { tolerance (77) }\end{array}$ & $11.4 \pm 0.4^{*}$ \\
\hline $\begin{array}{l}\text { Impaired fasting glycemia } \\
\text { (30) }\end{array}$ & $11.0 \pm 0.8^{*}$ \\
\hline $\begin{array}{l}\text { Impaired glucose } \\
\text { tolerance + Impaired } \\
\text { fasting glycemia (14) }\end{array}$ & $11.7 \pm 1,2^{*}$ \\
\hline
\end{tabular}

Note: * $p<0.001$ comparing to the group without carbohydrates metabolism disorders

Among people with IFG, only $25 \%$ had high DM risk (1520 points), $21 \%$ had moderate risk, 33\% had increased risk (7-11 points), and $21 \%$ had low risk (<7 points).

Fig.1. \% of subjects with and without carbohydrates metabolism disorders depending on the FINDRISK Score

No carbohydrates metabolism disorders

(1)

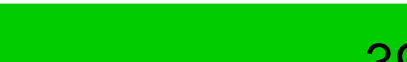

39

39,6

40,4

14,6

IFG

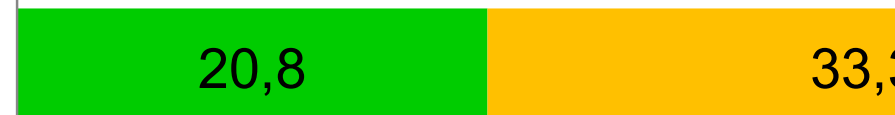

33,3

20,8

IGT

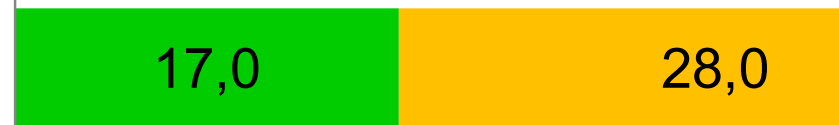

26,0

29,9

27,6

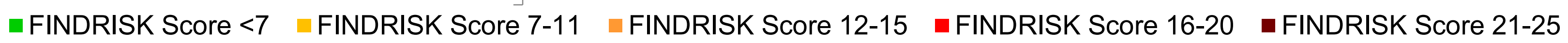

Conclusion: performing of OGTT only for Uzbek individuals with high and very high DM risk according FINDRISK questionnaire, would have miss reveal $66 \%$ of patients with diabetes. Probably, it is necessary to use anthropometric references specific for Uzbek nation, and also to perform integral assessment of type 2 DM risk factors for people of Uzbek nationality. 